\title{
Presenting offerings from pr-dt : the representation of the pr-dt: and its role in the tombs of the 5 th dynasty at giza and Saqqara
}

\section{maha R.yehia}

\section{abstract:}

the scenes of presenting the offerings to the tomb owner belong to the most poupular subjects of the old kingdome tomb decoration. Three main groups can be differentiated, the first type represents the delivery of offerings from the funerary estate pr-dt to the tomb owner, the offerings consist mainly of desert animals, cattle and fowl which come from pr-dt and are assigned to the invocation offering prt-xrw . the second type depicts and other comestibles to the offering place in long files . the third type finally consists in various workers who work in different kinds of offering and above them was mentioned that they are workers from pr-dt .all three types depict persons who are about to greet the deceased with the offerings they have in their hand .

the present article examines the scens of offering that came out from pr-dt to the tomb owner and investigates what kind of products delivered in those scenes . the examination will also assess to reveal the function of the pr-dt and its workers and their functions .it is important to know whether or not written regulations existed, which defined who was allowed to have which kind of offering. Did acentral department exist, which regulated this process? Tombs of fifth dynasty at giza and Saqqara cemeteries will be investigated within this farme work because of their textual and scenes evidence.

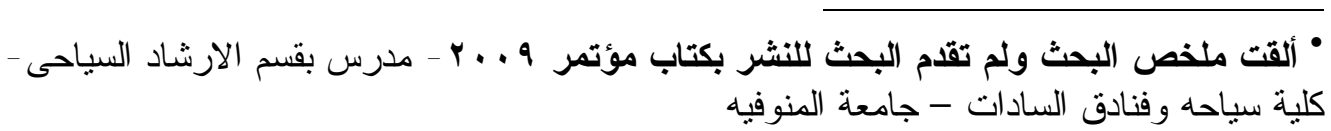

